\title{
0.355-micrometer direct detection wind lidar under testing during a field campaign in consideration of ESA's ADM-Aeolus mission
}

\author{
S. Lolli ${ }^{1, *}$, A. Delaval ${ }^{1, * *}$, C. Loth ${ }^{1}$, A. Garnier ${ }^{2, * * *}$, and P. H. Flamant ${ }^{1}$ \\ ${ }^{1}$ Laboratoire de Météorologie Dynamique - UMR8539, Ecole Polytechnique, Palaiseau, France \\ ${ }^{2}$ Laboratoire Atmosphères, Milieux, Observations Spatiales, CNRS-UVSQ-UPMC, Guyancourt, France \\ *now at: JCET-NASA, GSFC, Greenbelt, MD 20771, USA \\ *** on leave from LMD \\ **** now at: Science Systems Applications Inc./LaRC, Hampton, VA, USA
}

Correspondence to: S. Lolli (simone.lolli@nasa.gov)

Received: 27 April 2013 - Published in Atmos. Meas. Tech. Discuss.: 23 May 2013

Revised: 31 October 2013 - Accepted: 7 November 2013 - Published: 9 December 2013

\begin{abstract}
The atmospheric wind field information is a key issue to numerical weather prediction (NWP) and climate studies. The Atmospheric Dynamic Mission-Aeolus is currently developed by the European Space Agency (ESA) to launch a wind sensing Doppler lidar in mid-2015. The high spectral resolution lidar concept is using backscattered laser signals from molecules and particles to provide accurate horizontal wind velocity measurements in the depth of atmosphere. The Aeolus lidar, so-called ALADIN, will operate in $\mathrm{UV}$ at $0.355 \mu \mathrm{m}$. The combination of air molecules and UV laser light is intended to provide wind data evenly distributed everywhere in the lower atmosphere (below $30 \mathrm{~km}$ altitude). The goal of the ESA's Aeolus mission is to enhance the present meteorological observations system over sparse wind data regions, and more importantly to provide direct wind information in the tropics where no geostrophic wind can be derived from mass fields obtained from passive radiometer satellite. The $0.355 \mu \mathrm{m}$ lidar concept was under testing during a field campaign conducted at the Haute-Provence Observatory, France, in 1999. Several active remote sensors were deployed on the site, and it was the opportunity to address the self-consistency of wind measurements made by different lidars, a $72 \mathrm{MHz}$ radar, and conventional balloon radio soundings. The paper presents the comparison of different remote sensors using two criteria: Pearson cross-correlation coefficient and root mean square error. The methodology discussed here may be useful in future ESA Aeolus validation campaigns involving different kinds of instruments.
\end{abstract}

\section{Introduction}

The atmospheric wind field is essential to meteorology and climate studies. The world wide radio-sounding network is the backbone of the World Meteorological Organization (WMO), supplemented with aircraft, buoys and meteorological radars. Wind data are sparse and unevenly distributed between land and ocean and between the Northern Hemisphere and Southern Hemisphere. That is a major constraint to improve numerical weather prediction models (Courtier et al., 1992). In the last decades, satellite observations have helped to increase the global wind data set by adding (i) scatterometer winds, (ii) cloud track winds, and (iii) geostrophic winds derived from the mass field using temperature measurements.

In the 1980s, a new concept of satellite observations by a wind sensing lidar came into discussion (Huffaker et al., 1984). It was based on (i) a high-energy pulsed singlemode $\mathrm{CO}_{2}$ laser emitting at $10 \mu \mathrm{m}$ associated with heterodyne detection technique, and (ii) backscattering from aerosols and cloud particles. The NASA's LAWS project to deploy a wind sensing lidar in space raised the issue posed by the availability of sufficient particle backscatter coefficient everywhere. The NASA's Global Backscatter Experiment (GLOBE) project organized two airborne circumPacific aerosol backscatter surveys in 1989 and 1990 to address the issue. The NASA's DC8 aircraft carried several multiple wavelengths lidars and in situ probes (see Menzies et al., 1984, 1994; Menzies and Tratt, 1994, 1997). The analyses and modeling efforts conducted during the GLOBE 
project concluded to a limited capability of a $10 \mu \mathrm{m}$ lidar in space to profile tropospheric wind with the expected accuracy: $1 \mathrm{~m} \mathrm{~s}^{-1}$ in the lower troposphere and $2-3 \mathrm{~m} \mathrm{~s}^{-1}$ in the mid- and upper troposphere.

A new wind sensing lidar concept based on (i) backscattering from molecules and (ii) a single-mode $0.532 \mu \mathrm{m} \mathrm{Nd}-\mathrm{YAG}$ laser and direct detection technique was proposed (Chanin et al., 1989). Later, the technique was implemented at $0.355 \mu \mathrm{m}$ for better efficiency of molecular scattering according to a $\lambda^{-4}$ law dependence. Atmospheric molecules are uniformly distributed (according to pressure) with a known dependence in height so a $0.355 \mu \mathrm{m}$ lidar is the root for the ESA's Aeolus mission to be launched in mid-2015. The Aeolus mission is designed to fulfill the WMO requirements regarding vertical resolution and accuracy (see Stoffelen et al., 2005).

The Doppler technique with a high spectral resolution (HSR) lidar consists in sounding the atmosphere with a stabilized single frequency pulsed laser and measuring the frequency shift due to the Doppler effect: $\Delta v=-2 \frac{V_{\mathrm{r}}}{\lambda}$, of the backscattered signal spectrum (i.e., relative motion between the laser and the scatterer moving with the wind and then relative motion between the scatterer and receiver telescope). The Doppler frequency shift $\Delta v$ is in $\mathrm{Hz}, V_{\mathrm{r}}$ in $\mathrm{m} \mathrm{s}^{-1}$ the radial velocity along the lidar line of sight (LoS), and $\lambda$ (in $\mathrm{m}$ ) the laser wavelength. The horizontal velocity is $V_{\mathrm{h}}=V_{\mathrm{r}} / \sin \theta$, where $\theta$ is the angle between the lidar LoS and the nadir direction (Marseille and Stoffelen, 2003).

The wind sensing lidar techniques rely on the frequency shift of the backscattered spectra. The spectra are narrow in the case of particles and broad in the case of molecules according to thermal velocity distribution. At atmospheric pressure, the molecular spectra are not a single Gaussian line shape, but it includes a Brillouin doublet to result in the socalled Rayleigh-Brillouin spectra (Sugawara and Yip, 1967; Tenti et al., 1974; Tenti and Desai, 1974).

HSR lidars can retrieve the wind speed profile analyzing the signal backscattered from molecules or aerosols. In practice, the backscattered spectra are analyzed separately by two interferometers: a dual Fabry-Perot for the broad molecular spectra (Chanin et al., 1989; Korb and Genty, 1990; Garnier and Chanin, 1992; Gentry and Korb, 1994) and a Fizeau for the narrow particle spectra. Other alternative HSR techniques have been proposed: (i) Bruneau (2002) used a MachZehnder interferometer; (ii) Cezard et al. (2009) proposed a combination of two Michelson interferometers; and (iii) iodine notch filter has been proposed by Liu et al. (1997) and Friedman et al. (1997). On other hand, the heterodyne detection is better suited to analyze the frequency shift of narrow spectra associated with particles. In heterodyne detection lidar, the return signals are mixed with the beam of a local oscillator laser.

The wind lidar techniques were tested and validated one by one separately in field studies. For 0.532 or $0.355 \mu \mathrm{m}$ lidars and direct detection, see Chanin et al. (1989), Korb and Gentry (1990), Garnier and Chanin (1992), Gentry and
Korb (1994), McGill et al. (1997) and Korb et al. (1998). For $10.6 \mu \mathrm{m}$ lidar and heterodyne technique, see Post et al. (1982), Delville (1996) and Drobinski et al. (1998). In addition, airborne measurements have been conducted using a $10.6 \mu \mathrm{m}$ heterodyne detection lidar by Werner et al. (2001) and Reitebuch et al. (2001, 2003), and more recently using a $0.355 \mu \mathrm{m}$ direct detection lidar by Reitebuch et al. (2009) and Marksteiner et al. (2011). However, back in 1999 the selection of the ESA's Aeolus mission made use of the comprehensive comparison reported by Delaval et al. (2000a,b), of various lidar techniques (direct and heterodyne) with radio sounding and with a $72 \mathrm{MHz}$ radar. At the time, the $0.355 \mu \mathrm{m}$ direct detection lidar developed by the University of Geneva (UoG) was on site but still under testing and not officially involved.

In this paper we report the performances of the $0.355 \mu \mathrm{m}$ direct detection wind lidar (Double EDGe, or DEDG) developed at the University of Geneva (UoG) and the comparison with two other wind lidars: a $0.532 \mu \mathrm{m}$ direct detection lidar and a $10.6 \mu \mathrm{m}$ heterodyne detection lidar, and a $72 \mathrm{MHz}$ radar. The field campaign took place at the Haute-Provence Observatory (OHP, $44^{\circ} \mathrm{N}, 6^{\circ} \mathrm{E}$ ), France, in July 1999 (Delaval et al., 2000a,b). The three wind lidars were operated side by side. The $10.6 \mu \mathrm{m}$ heterodyne detection lidar was designed and operated by Laboratoire de Météorologie Dynamique (Delville, 1996; Drobinski et al., 1998). The $0.532 \mu \mathrm{m}$ direct detection lidar (Chanin et al., 1989; Garnier and Chanin, 1992; Chanin et al., 1994) was designed and operated by Service d'Aéronomie, now LATMOS.

The objectives of the field campaign were to compare the performances of different remote sensors (lidar, radar) and radio sounding in various meteorological conditions, in order to verify that the retrieved wind velocities are basically the same (within a statistical error) most of the time, and to explain the differences associated with complex meteorological situations. The lidars are expected to provide the same wind velocities when operated side by side, pointing in the same direction with similar range resolution and sufficient signal to noise ratio (SNR). SNR relies on atmospheric backscattering property (it is function of operating wavelength) and instrument design (laser energy per receiver area, detection technique).

\section{UoG's $0.355 \mu \mathrm{m}$ direct detection wind lidar}

Gentry et al. (2000) and then Flesia et al. (2000) performed the first wind measurements at $0.355 \mu \mathrm{m}$. The University of Geneva (Flesia and Korb, 1999) makes use of the NASAGSFC technology. A Fabry-Perot interferometer provides the so-called edges (filter band pass) symmetrically located with respect to the probing laser frequency (Fig. 1). The three band passes are obtained with step etalons on a single pair of etalon plates. Long-term frequency drift of the transmitter 


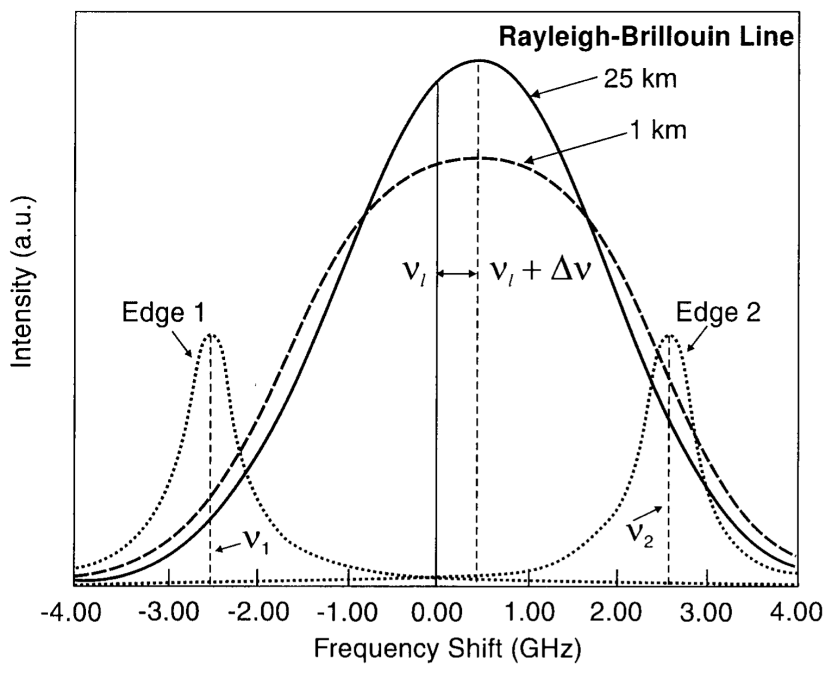

Fig. 1. Measurement of the slight frequency shift of a RayleighBrillouin line shape by means of two edge filters located at frequencies $v_{1}$ and $v_{2}$ with respect to the laser frequency $v l$ (Flesia and Korb, 1999).

laser and the drift of the capacitively stabilized etalon are removed by locking the Fabry-Perot interferometer to the laser frequency (Fig. 1).

The backscattered signals are collected by a $25 \mathrm{~cm}$ diameter telescope and focused onto a multimode optical fiber cable. The resulting field of view is equal to $0.125 \mathrm{mrad}$. The light transmitted by the fiber is collimated and directed onto the Fabry-Perot interferometer that serves as double-edge filter (each spectral bandwidth is equal to $1.55 \mathrm{GHz}$, full width at half maximum). The two edges are located about the laser frequency with a separation of $\pm 2.60 \mathrm{GHz}$. This corresponds to the crossover point where the sensitivity (i.e., the percent change in signal per $\mathrm{m} \mathrm{s}^{-1}$ ) is the same for the molecular and aerosol signals. Also, these parameter values enable the smallest measurement error (Flesia and Korb, 1999). The UoG instrumental parameters are summarized in Table 1. Preliminary measurements performed at UoG show a good agreement in the $2-10 \mathrm{~km}$ altitude range with the Payerne radio sounding located $60 \mathrm{~km}$ east of Geneva (Flesia et al., 2000).

After a relevant signal accumulation, the wind velocity profile is retrieved assuming that the vertical velocity contribution is negligible with respect to the horizontal wind velocity. For calibration purposes during field experiments, the lidar is pointed to zenith every $10 \mathrm{~min}$. A full description of the retrieval method can be found in Flesia et al. (1999). The basic information to retrieve the frequency shift and wind velocity is the intensity ratio $R=\frac{I_{1}}{I_{2}}$, between intensities $I_{1}$ and $I_{2}$ transmitted by edges 1 and 2 , respectively. Accordingly, the wind profile $V(r)$ retrieved from range gate $r$ is

$V(r)=\frac{1}{\vartheta}\left[\frac{R(r)-R_{\mathrm{vert}}(r)}{R_{\mathrm{vert}}(r)}\right]$,
Table 1. $0.355 \mu \mathrm{m}$ lidar technical characteristics. Referring to Fig. 1 , the three Fabry-Perot interferometers are the edges, two of them located on the wings of the backscattered Rayleigh-Brillouin spectrum and the third one locked to the laser frequency.

\begin{tabular}{ll}
\hline Laser wavelength & $0.355 \mu \mathrm{m}$ \\
Laser energy per pulse & $80 \mathrm{~mJ}$ \\
Pulse repetition frequency & $30 \mathrm{~Hz}$ \\
Laser divergence & $0.5 \mathrm{mrad}$ \\
Telescope diameter & $25 \mathrm{~cm}$ \\
Telescope field of view & $0.125 \mathrm{mrad}$ \\
Etalon plate spacing & $1.25 \mathrm{~cm}$ \\
Effective finesse & 7.7 \\
Etalon spectral bandwidth & $1.56 \mathrm{GHz}$ \\
Number of etalon channels & 3 \\
Laser etalon separation-locking Ch. & $0.78 \mathrm{GHz}$ \\
Laser etalon separation atm. Ch. & $\pm 2.605 \mathrm{GHz}$ \\
\hline
\end{tabular}

where $R(r)$ and $R_{\text {vert }}(r)$ represent the intensity ratio in range gate $r$ (i.e. $R_{\text {vert }}=1$ assuming vertical velocity negligible) for slant and vertical pointing directions, respectively, and $\vartheta$ is the sensitivity of the system.

\section{Field campaign}

The field campaign took place at the Observatoire de HauteProvence (OHP, $44^{\circ} \mathrm{N}, 6.2^{\circ} \mathrm{E}$ ) in southern France from 12 to 23 July 1999 (Delaval et al., 2000a,b). The station is $650 \mathrm{~m}$ above sea level.

\subsection{Instrument overview and objectives}

The wind velocity measurements taken by the $0.355 \mu \mathrm{m}$ Doppler lidar are compared to the following:

- a $0.532 \mu \mathrm{m}$ direct detection dual Fabry-Perot Doppler lidar (DC-DDL). This lidar had been operated on a regular basis since the early 1990s at OHP (Souprayen et al., 1999a). The system was designed mostly for stratospheric observation at nighttime (in practice for altitude above $8 \mathrm{~km}$ in clear atmospheric conditions). The characteristics of the dual Fabry-Perot etalon were chosen to minimize the sensitivity to particle scattering (Souprayen et al., 1999b). The laser source was a frequency doubled $Q$ switched single-mode Nd:YAG laser. The repetition rate was $30 \mathrm{~Hz}$, and the energy per pulse was $130 \mathrm{~mJ}$ at $0.532 \mu \mathrm{m}$. The instrument was modified for the campaign to enable nighttime and daytime operations from about $2 \mathrm{~km}$ up to $20 \mathrm{~km}$ altitude. The receiver was composed of two $50 \mathrm{~cm}$ diameter parabolic mirrors. A $0.3 \mathrm{~nm}$ band-pass interference filter with $30 \%$ peak transmission was used to reduce the sky background light during daytime operations.

- a $10.6 \mu \mathrm{m}$ heterodyne detection lidar (HDL-LMD). This transportable wind lidar implemented a pulsed 
Table 2. For each instrument is reported the max range of measurement, the spatial resolution along the LoS, the measurement configuration (LoS azimuthal and elevation angles), the temporal resolution and the instrumental average error. The error interval is related to the min and max error along the profile.

\begin{tabular}{llclll}
\hline Instrument & Range $\max$ & Spatial res. & LoS & Temp. res. & Instr. error \\
\hline $0.532 \mu \mathrm{m}$ DC-DDL & $\begin{array}{l}\text { Day: } 2-20 \mathrm{~km} \\
\text { Night: } 2-30 \mathrm{~km}\end{array}$ & $115 \mathrm{~m}$ & $40^{\circ} \mathrm{N}-\mathrm{E}$ & $30 \mathrm{~min}$ & $1.1-3.8 \mathrm{~m} \mathrm{~s}^{-1}$ \\
& & & & \\
$10.6 \mu \mathrm{m}$ HDL-LMD & $1.5-12 \mathrm{~km}$ & $250 \mathrm{~m}$ & $40^{\circ} \mathrm{N}-\mathrm{E}$ & $1 \mathrm{~min}$ & $0.4-0.8 \mathrm{~m} \mathrm{~s}^{-1}$ \\
$0.355 \mu \mathrm{m}$ DEDG & $1-12 \mathrm{~km}$ & $380 \mathrm{~m}$ & $40^{\circ} \mathrm{N}-\mathrm{E}$ & $12 \mathrm{~min}$ & $1.2-3 \mathrm{~m} \mathrm{~s}^{-1}$ \\
ST-Radar 72 MHz & $2-15 \mathrm{~km}$ & $375 \mathrm{~m}$ & $15^{\circ} \mathrm{N}-\mathrm{E}-\mathrm{S}-\mathrm{W}$ & $15 \mathrm{~min}$ & N/A \\
\hline
\end{tabular}

single longitudinal mode $\mathrm{TE}-\mathrm{CO}_{2}$ laser transmitting $300 \mathrm{~mJ}$ in a pulse length duration of $2.5 \mu \mathrm{s}$ at a $10 \mathrm{~Hz}$ pulse repetition frequency. The shot-to-shot frequency fluctuation was about $5 \mathrm{MHz}$; the measured spectral bandwidth was less than $0.8 \mathrm{MHz}$. The atmospheric signals were photo-mixed with the beam of a continuous wave $\mathrm{CO}_{2}$ local laser. A $17 \mathrm{~cm}$ telescope collected the atmospheric signals. The lidar LoS can be scanned or pointed in any direction. Each lidar signal was processed as an independent realization. Later on, the frequency estimations were accumulated to improve the overall performances.

The main technical characteristics of each instrument and their spatio-temporal resolutions are summarized in Table 2. The vertical resolution varies with probing pulse length and line-of-sight pointing direction.

The lidar wind velocity estimates are compared to the following:

1. Two radio soundings (RSs)

- radio soundings performed at OHP during the experiment,

- radio soundings performed at 12:00 and 23:00 UTC daily at Nîmes Météo-France station (about $100 \mathrm{~km}$ southeast of OHP).

2. OHP radar

- a $72 \mathrm{MHz}$ radar for stratospheric-tropospheric observations (Woodman and Guillen, 1974). The radar transmission-reception antenna is an array of 32 dipoles covering a $45 \times 45 \mathrm{~m}^{2}$ area. It emits EM microsecond pulses with an average power of $1 \mathrm{~kW}$ at a pulse repetition frequency of $6400 \mathrm{~Hz}$, in five directions: vertical, north, east, south, west, sequentially, at a $15^{\circ}$ elevation angle.

3. Outputs of numerical weather prediction models

- ECMWF analyses at 12:00 and 18:00 UTC.

An objective of the campaign was to assess the lidar performance in cloudy and clear air conditions (favorable or detrimental according to the lidar techniques). We used the GPS radio soundings performed at OHP as a reference. Another objective was to evaluate the relative contributions of instrumental errors and representativeness errors.

The 0.355 and $0.532 \mu \mathrm{m}$ direct detection lidars make use of signals backscattered by molecules and small particles (particle size with respect to the laser wavelength) while the $10.6 \mu \mathrm{m}$ lidar relies on bigger particles. The signals dynamic ranges of the 0.355 and $0.532 \mu \mathrm{m}$ direct detection lidars are not sufficient to handle scattering by the bigger particles that saturate the detectors used in photon counting mode. The $72 \mathrm{MHz}$ radar wavelength is of the order of $4 \mathrm{~m}$. The effective scatterers are turbulence clusters of the order of $2 \mathrm{~m}$. The $72 \mathrm{MHz}$ radar measurement capability is limited in the presence of laminar flow.

\subsection{Atmospheric measurements}

The lidar LoS measurements were fixed at a $40^{\circ}$ zenithal angle and alternately switched from east to north directions. The measurements were taken during $1 \mathrm{~h}$. The $72 \mathrm{MHz}$ radar was operated continuously to retrieve two horizontal wind components and the vertical velocity (Delaval et al., 2000a,b). Radio soundings with GPS tracking system were launched from OHP during every set of measurements.

Twelve data sets are chosen for the comparison, as reported in Table 3. The measurements were taken in different atmospheric conditions: clear sky, strong winds, and high aerosol loadings. As a general policy during the field campaign, the results were provided only a few hours after the measurement periods to conduct blind comparisons.

\section{Methodology for comparison between wind sensors}

Two criteria are chosen to quantify the difference between wind profiles: Pearson cross-correlation coefficient (CC) and root mean square error (RMSE). These two criteria are complementary. The CC compares the profile shapes two by two, whereas the RMSE calculates the average absolute value of the difference in wind velocity. The same number of measurements at the same spatial resolution is used in the statistical analyses. The two sets of variables to be compared are wind velocities. A linear relationship is expected and some 
Table 3. Selected data sets for intercomparison with radio sounding measurements and relative weather conditions.

\begin{tabular}{lccccc}
\hline Set & Date & $\begin{array}{c}\text { Starting time } \\
\text { UTC }\end{array}$ & $\begin{array}{c}\text { Ending time } \\
\text { UTC }\end{array}$ & Balloon & Direction \\
\hline V2.4 & 14 Jul 1999 & 1500 & 1600 & 1521 & E \\
& & 1600 & 1700 & & N \\
V2.14 & 19 Jul 1999 & 1500 & 1600 & 14.57 & N \\
& & 1600 & 1700 & & E \\
V2.17 & 20 Jul 1999 & 2230 & 2315 & 2241 & E \\
& & 2315 & 0000 & & N \\
V2.18 & \multirow{2}{*}{ 21 Jul 1999 } & 2000 & 2100 & 2059 & N \\
& & 2100 & 2200 & & E \\
V2.20 & 22 Jul 1999 & 2000 & 2100 & 2022 & N \\
& & 2100 & 2200 & & E \\
V2.22 & 23 Jul 1999 & 1500 & 1600 & 1523 & N \\
& & 1600 & 1700 & & E \\
\hline
\end{tabular}

scatter of the data may occur due to statistical error and bias. In the case of constant bias, the linear dependence does not change. If the bias is not constant with altitude, there is a change in slope plus a translation. In practice, $\mathrm{CC}>0.7$ suggests strong correlation, while $0.3<\mathrm{CC}<0.7$ would stand for moderate correlation. The coefficient of determination that is equal to $\mathrm{CC}^{2}$ quantifies the proportion of the variance of one wind velocity set explained by the other. By definition, the RMSE (see Eq. 3) includes standard deviation and bias. A comparison of $\mathrm{CC}^{2}$ and RMSE indicates the importance of bias in the statistical analyses of the two data sets.

\subsection{Cross-correlation coefficient}

The Pearson CC between two wind profiles measured by two different instruments having the same spatial resolution along the LoS is

$C=\frac{\frac{1}{n} \sum_{i}\left(x_{i}-\bar{X}\right)\left(y_{i}-\bar{Y}\right)}{\sigma_{x} \sigma_{y}}$.

$X$ and $Y$ are wind velocity profiles, $n$ the total number of range bins, and $x_{i}$ and $y_{i}$ the $i$ th value of $X$ and $Y$ respectively. $\bar{X}$ and $\bar{Y}$ are the respective average values of $X$ and $Y$ over the $n$ considered values, and $\sigma_{x}$ and $\sigma_{y}$ are the standard deviations of $X$ and $Y$ over the $n$ considered values, respectively.

$\mathrm{CC}$ is not reliable when computed on a small number of measurements for each data set. Spurious correlations displaying two-tailed probability occur when a small number of measurements is used ( 5 as an example). The spurious correlations are negligible when 20 measurements are used (probability of spurious correlations is less than $1 \%$ ).

\subsection{Root mean square error}

It is calculated as

$\Delta V(X Y)=\sqrt{\frac{\sum_{i=1}^{n}\left(x_{i}-y_{i}\right)^{2}}{n}}$,

where $\Delta V(X Y)$ is the average deviation between the two wind profiles, $x_{i}$ and $y_{i}$ the wind speed at $i$ th bin, and $n$ the total number of range bins.

Supposing that the errors have a normal distribution, a statistically significant accuracy on RMSE requires 20 points to achieve a $95 \%$ confidence level. Then it is acceptable that one point may exceed the computed accuracy (see National Standard for Spatial Data Accuracy, 1998)

CC and RMSE values among different instruments are calculated for wind profiles that have at least 20 points.

\section{Results}

The wind profiles are interpolated on the same spatial resolution before the CC and RMSE computations. The altitude range is divided in two parts: lower troposphere (up to $5 \mathrm{~km}$ a.s.1. - above sea level) and upper troposphere (from 5 to $20 \mathrm{~km}$ a.s.1.). For each set of measurements, the on-site radio sounding is taken as reference.

\subsection{Cross-correlation coefficient}

The cross-correlation coefficient computed at all altitudes for each instrument vs. radio sounding is higher than 0.7 and higher than 0.8 in the east direction (Table $4 \mathrm{a}$, values in last column), indicating a strong correlation. Then, the lidar and radar wind profiles are in agreement with the radio soundings, even if, under strong wind conditions, the balloon can drift far away from the site. The cross-correlation coefficient between two instruments sometimes shows a lower correlation. Possible causes are discussed further.

Regarding the correlation against radio sounding, better correlations are shown in the east direction than in the north direction. This is due to the location of OHP site with respect to a valley oriented in the east-west direction, surrounded by two hills: the "Lure" to the north and the "Luberon" to the south. The wind fluctuations due to orography are then more likely meridional than zonal especially in strong wind conditions (mistral) as shown in Fig. 3. The effects are expected to be stronger below $5 \mathrm{~km}$. The instrument spatial resolution is an important variable, especially in the lower troposphere. For these reasons, the remote sensors may not follow the wind fluctuations as recorded by radio soundings.

The CCs were also calculated for each pair of instruments. The values provided evidence of moderate to poor correlations between direct detection and heterodyne detection techniques. A plausible reason is the particle loading. Generally, 
Table 4. (a) Average cross-correlation coefficients over the whole troposphere (the cross-correlation is calculated for those profiles containing at least 20 measurement points; HDL-LMD, depending on atmospheric conditions, could take measurements in the upper troposphere, when aerosol layers or clouds are present) between the wind profiles retrieved by the different instruments for east (upper) and north (lower) direction. (b) Average cross-correlation coefficients over the lower troposphere $(0-5 \mathrm{~km})$ between the wind profiles retrieved by the different instruments on selected data sets and radio sounding for east (upper) and north (lower) direction. (c) Average cross-correlation coefficients over the upper troposphere (5$15 \mathrm{~km}$ ) between the wind profiles retrieved by the different instruments on selected data sets and radio sounding for east (upper) and north (lower) direction.

\begin{tabular}{|c|c|c|c|c|c|}
\hline $\begin{array}{l}\text { Average } \\
\text { value }\end{array}$ & $\begin{array}{l}0.532 \mu \mathrm{m} \\
\mathrm{DC}-\mathrm{DDL}\end{array}$ & $\begin{array}{l}0.355 \mu \mathrm{m} \\
\text { DEDG }\end{array}$ & $\begin{array}{l}10.6 \mu \mathrm{m} \\
\text { HDL-LMD }\end{array}$ & $\begin{array}{l}\text { Radar } \\
\text { ST }\end{array}$ & $\mathrm{RS}$ \\
\hline \multicolumn{6}{|c|}{ (a) } \\
\hline \multicolumn{6}{|c|}{ East direction } \\
\hline $0.532 \mu \mathrm{m}$ DC-DDL & 1 & 0.89 & 0.51 & 0.75 & 0.9 \\
\hline $0.355 \mu \mathrm{m}$ DEDG & 0.89 & 1 & 0.64 & 0.79 & 0.83 \\
\hline 10.6 $\mu \mathrm{m}$ HDL-LMD & 0.51 & 0.64 & 1 & 0.79 & 0.92 \\
\hline Radar ST & 0.75 & 0.79 & 0.79 & 1 & 0.92 \\
\hline RS & 0.90 & 0.83 & 0.92 & 0.92 & 1 \\
\hline \multicolumn{6}{|c|}{ North direction } \\
\hline $0.532 \mu \mathrm{m}$ DC-DDL & 1 & 0.79 & 0.62 & 0.61 & 0.77 \\
\hline $0.355 \mu \mathrm{m}$ DEDG & 0.79 & 1 & 0.58 & 0.66 & 0.73 \\
\hline $10.6 \mu \mathrm{m}$ HDL-LMD & 0.62 & 0.58 & 1 & 0.65 & 0.82 \\
\hline Radar ST & 0.61 & 0.66 & 0.65 & 1 & 0.82 \\
\hline RS & 0.77 & 0.73 & 0.82 & 0.82 & 1 \\
\hline \multicolumn{6}{|c|}{ (b) } \\
\hline Average value & 0.75 & 0.71 & 0.85 & 0.77 & \\
\hline Average value north & 0.59 & 0.61 & 0.80 & 0.66 & \\
\hline Average value east & 0.91 & 0.81 & 0.90 & 0.88 & \\
\hline \multicolumn{6}{|c|}{ (c) } \\
\hline Average value & 0.80 & 0.84 & N/A & 0.83 & \\
\hline $\begin{array}{l}\text { Average value north } \\
\text { direction }\end{array}$ & 0.73 & 0.77 & N/A & 0.76 & \\
\hline $\begin{array}{l}\text { Average value east } \\
\text { direction }\end{array}$ & 0.87 & 0.89 & N/A & 0.90 & \\
\hline
\end{tabular}

each instrument has a stronger correlation with radio sounding than with other remote sensors (the performances are subject to atmospheric conditions). CC values represented in Table $4 \mathrm{a}-\mathrm{c}$ are an average of the $\mathrm{CC}$ over the measurement data sets.

Table $4 \mathrm{~b}$ shows the CCs computed with respect to radio sounding for the lower troposphere $(0-5 \mathrm{~km})$. We can notice a slight decrease in $\mathrm{CC}$ average values with respect to Table $4 \mathrm{a}-$ it has a stronger effect in north than in east LoS direction. Measurements taken to the north direction are more sensitive to the topography effects. This is due to the location of OHP. In the east direction, the agreement at low altitudes is quite the same as for the whole range of altitudes (i.e., no influence of topography). Mistral is an important meteorological phenomenon at low altitudes near the surface. This is confirmed by the results shown in Table 4c, where
Table 5. (a) Average root mean square error retrieved on selected data sets between the wind velocities retrieved by the different instruments and those provided by the radio sounding on selected cases. The instrumental error interval shows the min and max uncertainty along the profile, corresponding to the measurement range interval specified in Table 2 for each instrument. (b) Average root mean square error retrieved on selected data sets between the wind velocities retrieved by the different instruments and those provided by the radio sounding on selected cases on lower troposphere $(0-$ $5 \mathrm{~km}$ ). (c) Average root mean square error on upper troposphere $(5-20 \mathrm{~km})$ as retrieved on selected data sets between the wind velocities retrieved by the different instruments and those provided by the radio sounding on selected cases.

\begin{tabular}{|c|c|c|c|c|}
\hline & $\begin{array}{l}0.532 \mu \mathrm{m} \\
\mathrm{DC}-\mathrm{DDL}\end{array}$ & $\begin{array}{l}0.355 \mu \mathrm{m} \\
\text { DEDG }\end{array}$ & $\begin{array}{l}10.6 \mu \mathrm{m} \\
\text { HDL-LMD }\end{array}$ & $\begin{array}{c}\text { Radar } \\
\text { ST }\end{array}$ \\
\hline \multicolumn{5}{|c|}{ (a) } \\
\hline Average value $\left(\mathrm{m} \mathrm{s}^{-1}\right)$ & 3.40 & 3.67 & 1.64 & 2.30 \\
\hline Average value north $\left(\mathrm{m} \mathrm{s}^{-1}\right)$ & 3.99 & 3.51 & 1.66 & 2.25 \\
\hline Average value east $\left(\mathrm{m} \mathrm{s}^{-1}\right)$ & 2.89 & 3.12 & 1.63 & 2.35 \\
\hline Instrumental error $\left(\mathrm{m} \mathrm{s}^{-1}\right)$ & $1.1-3.8$ & $1.2-3$ & $0.4-0.7$ & N/A \\
\hline \multicolumn{5}{|c|}{ (b) } \\
\hline Average value $\left(\mathrm{m} \mathrm{s}^{-1}\right)$ & 2.12 & 2.18 & 1.64 & 1.86 \\
\hline Average value north $\left(\mathrm{m} \mathrm{s}^{-1}\right)$ & 2.3 & 2.5 & 1.66 & 1.89 \\
\hline Average value east $\left(\mathrm{m} \mathrm{s}^{-1}\right)$ & 1.95 & 1.86 & 1.63 & 1.73 \\
\hline \multicolumn{5}{|c|}{ (c) } \\
\hline Average value $\left(\mathrm{m} \mathrm{s}^{-1}\right)$ & 4.31 & 4.35 & 1.43 & 2.55 \\
\hline Average value north $\left(\mathrm{m} \mathrm{s}^{-1}\right)$ & 5.18 & 4.86 & 1.35 & 2.46 \\
\hline Average value east $\left(\mathrm{m} \mathrm{s}^{-1}\right)$ & 3.56 & 3.85 & 1.51 & 2.65 \\
\hline
\end{tabular}

the CCs calculated for the high troposphere $(5-20 \mathrm{~km})$ show better correlations with radio sounding than in the lower troposphere. The $0.355 \mu \mathrm{m}$ lidar shows a stronger correlation with radio sounding at higher altitudes due to the stronger molecular backscattering at this wavelength.

It may seem contradictory that, for certain instruments, the average cross-correlation coefficient is higher if calculated on the whole troposphere than on lower $(0-5 \mathrm{~km})$ or upper $(5-20 \mathrm{~km})$ troposphere respectively. A reason is that some wind profiles are excluded from the calculation as they do not meet the requirement to have at least 20 points of measurements.

\subsection{Root mean square error}

Considering the whole range of altitudes, Table 5a shows an average absolute deviation between 1.7 and $3.7 \mathrm{~m} \mathrm{~s}^{-1}$. Compared with the cross-correlation coefficients, there are no discrepancies between north and east directions. Table 5a also shows, for each instrument, the uncertainty interval on wind velocity retrievals. For the $0.355 \mu \mathrm{m}$ lidar (and in general for all the lidars), the uncertainty is range dependent. For example, at $10 \mathrm{~km}$, the error is more likely to be $3 \mathrm{~m} \mathrm{~s}^{-1}$ (calculated over $20 \mathrm{~s}$ integration, or 600 shots; Flesia et al., 2000). 

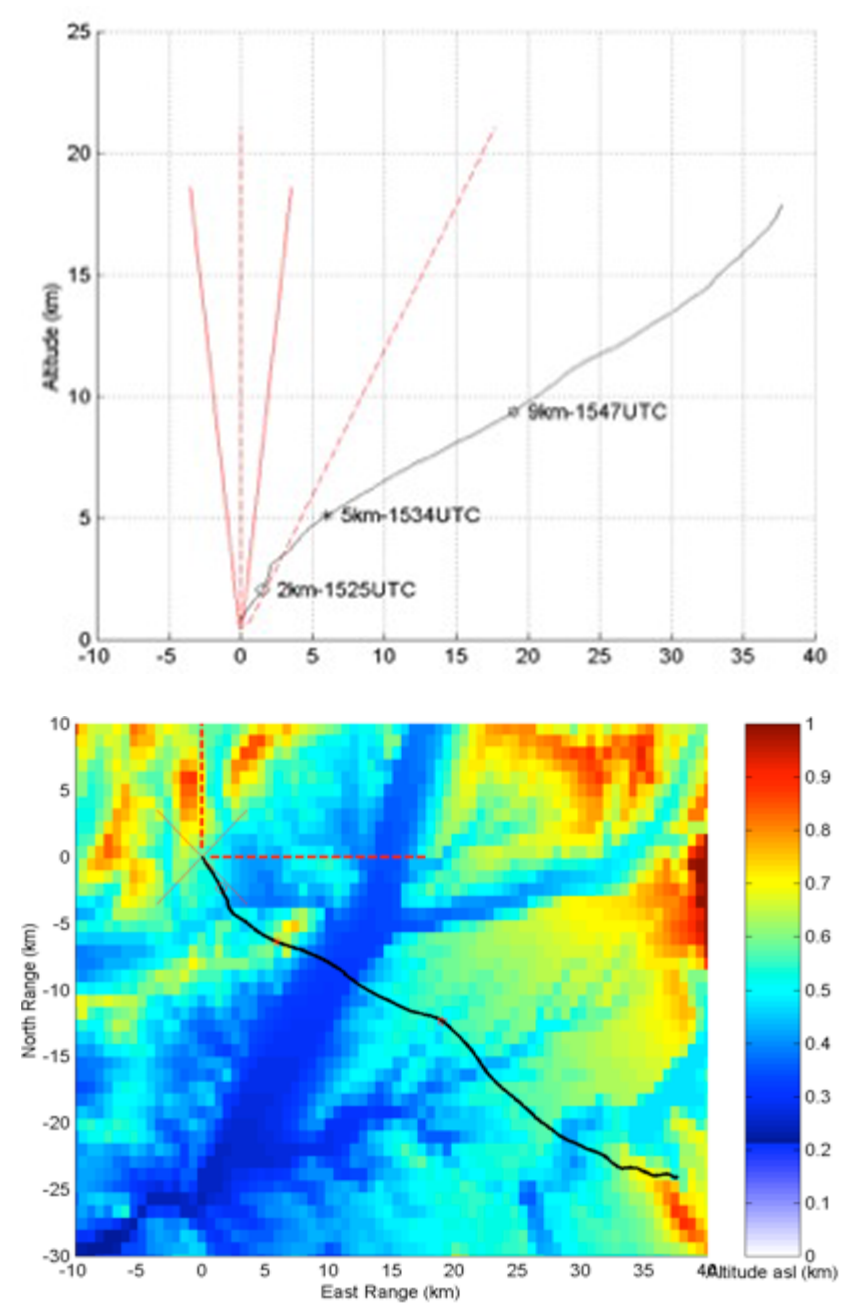

Fig. 2. Balloon trajectory with the underlying topography surrounding OHP (cross) on 14 July 1999. The balloon passes the valley (deep blue) at altitudes between 6 and $7 \mathrm{~km}$ a.s.l., whereas the lidar line of sight crosses this valley between 10 and $12 \mathrm{~km}$ a.s.l. (east LoS). The orographic effect of the valley on wind speed measurement is stronger on radio sounding.

For the other instruments, the uncertainty interval values (corresponding to minimum and maximum error along the wind velocity profile) can be found in Souprayen et al. (1999a,b), Delville (1996) and Drobinski et al. (1998).

The results show that the $10.6 \mu \mathrm{m}$ HDL-LMD is more accurate at lower altitudes. As shown in Fig. 5, the $0.532 \mu \mathrm{m}$ lidar has a bias substantially higher. Several causes may explain this bias. Common to all instruments is the influence of topography, especially for LoS toward the north, as different volumes are sounded, especially for the $72 \mathrm{MHz}$ radar and radio soundings (the balloon drifts away from the site due to strong winds; Fig. 2). The data interpolation smooths the wind profile introducing an error. It is very important to separate RMSE calculation from lower troposphere to higher
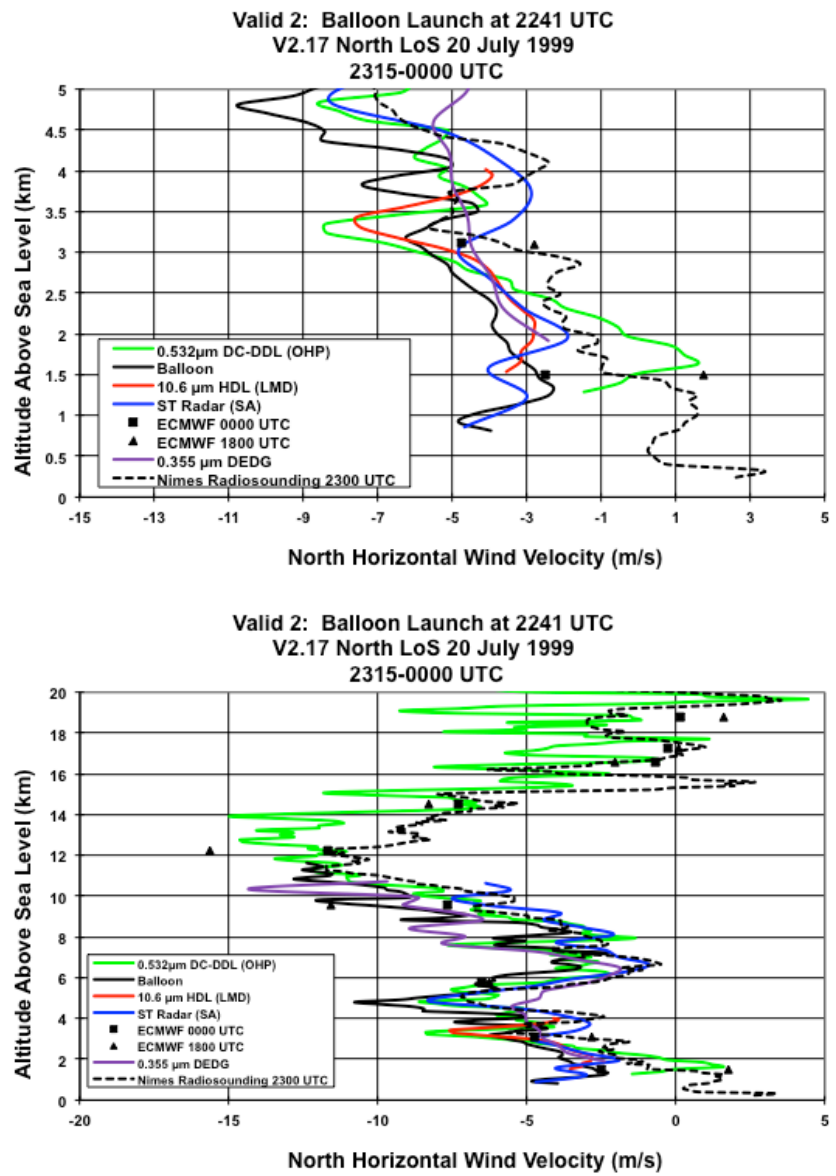

Fig. 3. Strong meridional mistral winds observed on 20 July 1999 between 23:15 and 24:00 UTC by the $0.355 \mu \mathrm{m}$ lidar (purple), the $0.532 \mu \mathrm{m}$ lidar (green), the $10.6 \mu \mathrm{m}$ lidar (red), and the $72 \mathrm{MHz}$ radar (blue). The OHP radio sounding was launched at 22:41 UTC (black solid line) and the Nîmes radio sounding at 23:00 UTC (black dashed line). The triangles and squares are from ECMWF runs at 18:00 and 00:00 UTC on 21 July, respectively. The top panel is zoomed between 0 and $5 \mathrm{~km}$ altitude.

troposphere, where different wind conditions may prevail: mistral in lower troposphere, jet stream in upper troposphere.

Table $5 \mathrm{~b}$ shows the RMSE calculated in the first $5 \mathrm{~km}$. The RMSE is lower than considering the whole profile, especially for direct detection technique instruments and $72 \mathrm{MHz}$ radar.

At lower altitudes the $0.355 \mu \mathrm{m}$ lidar retrievals are biased in the presence of large aerosol content and clouds. Even if, as stated in Flesia and Korb (1999), the Fabry-Perot interferometers are tuned at the crossover region where the sensitivity to the molecular signal is equal to the aerosol signal, the crossover region is not unique, but depends on atmospheric conditions and temperature and humidity. During the field campaign, the $0.355 \mu \mathrm{m}$ lidar was optimized for an altitude of $5 \mathrm{~km}$ by setting up the crossover region, i.e., the distance between the Fabry-Perot band passes and the laser line, at 3.32 times the half-width at half maximum 


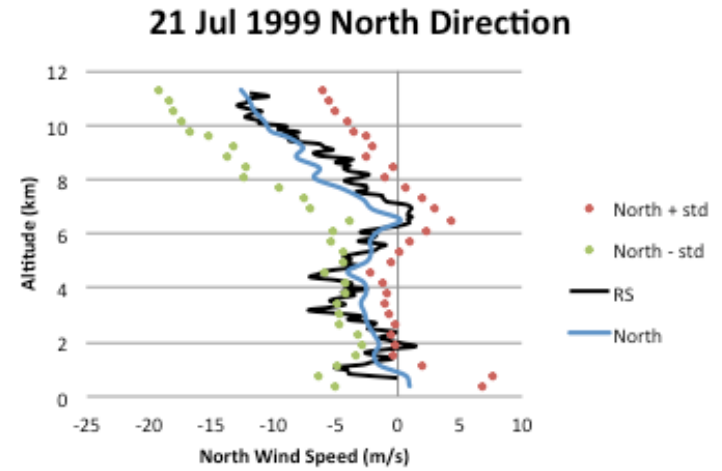

21 Jul 1999 East Direction

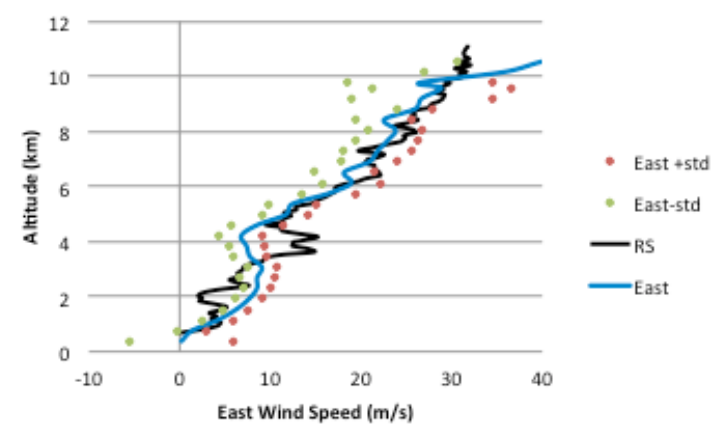

Fig. 4. Wind profiles from the $0.355 \mu \mathrm{m}$ lidar (mean in blue; mean + standard deviation in red; mean - standard deviation in green) compared with the OHP radio sounding (black, launched at 20:59 UTC) on 21 July 1999 for the north (upper panel, 20:0021:00 UTC) and east (lower panel, 21:00-22:00 UTC) directions.

of the band passes (Flesia and Korb, 1999). In Fig. 4, on 21 July 1999, both north and east lines of sight show an absolute deviation at lower altitudes larger than the instrumental error (east: around 2 and $4 \mathrm{~km}$, north: around 2, 3 and $4.3 \mathrm{~km}$ ). In this case, the atmospheric condensation at dusk changes both the aerosol microphysics and optical properties, due to higher humidity.

Table $5 c$ presents the RMSE values for higher troposphere $(5-20 \mathrm{~km})$. The values for higher altitudes are larger than for lower altitude. This is because the $10.6 \mu \mathrm{m}$ HDL does not retrieve wind velocity all the time above $5 \mathrm{~km}$ and below cirrus jet stream. In jet stream conditions, large discrepancies in wind speed measurements between RS and remote sensing instruments are observed. Table $4 \mathrm{a}$ shows very high CC values for $0.532 \mu \mathrm{m}$ DC-DDL and $0.355 \mu \mathrm{m}$ DEDG. These values for the north direction, and partially for the east direction, are higher than the cross-correlation coefficients calculated for each instrument with respect to radio sounding. This tells us that probably the lidars are sounding different atmospheric volumes with respect to the radio soundings, due to strong wind at high altitude (in the presence of a polar jet stream).

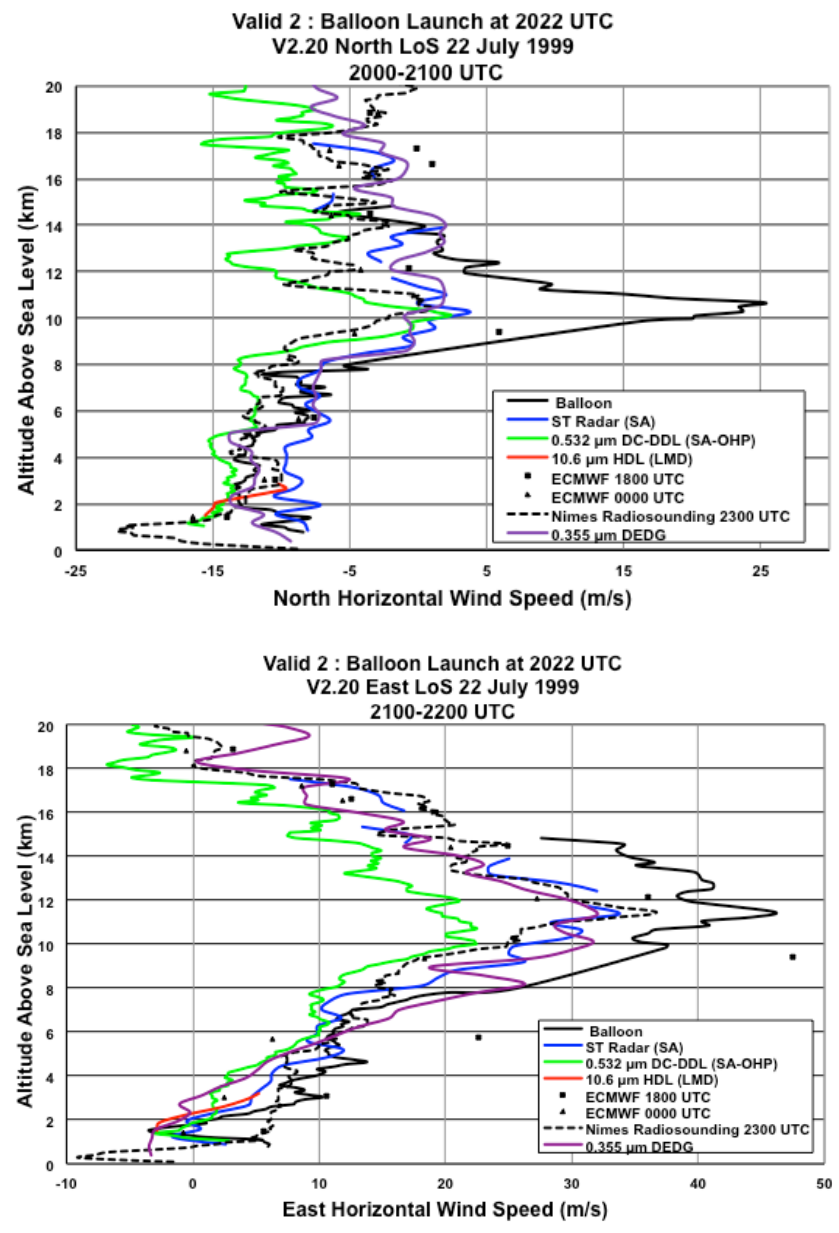

Fig. 5. Wind profile comparisons on 22 July 1999 with the same presentation as in Fig. 3. Upper panel: north direction between 20:00 and 21:00 UTC; lower panel: east direction between 21:00 and 22:00 UTC, with a strong jet stream at the tropopause. The OHP radio sounding was launched at 20:22 UTC.

\subsection{Discrepancies observed due to different meteorological conditions}

We observed, in certain cases, discrepancies between different instruments. These cases are of interest to discuss the limitations due to meteorological conditions. For example, when low clouds are present, the direct detection Doppler wind lidars are not reliable while the heterodyne Doppler lidar extends its measurement capability up to $10 \mathrm{~km}$.

On 22 July 1999 there was a strong mistral event; Fig. 5 shows disagreements in wind estimates. Strong winds induce gravity waves at low altitudes with significant vertical velocity that biases horizontal wind velocity estimates.

Discrepancies between the $72 \mathrm{MHz}$ radar, 0.532 and $0.355 \mu \mathrm{m}$ lidar instruments are observed near the tropopause (9-13 km altitude) during jet-stream episodes as reported on data set V2.20 in east direction, on 22 July 1999 (Fig. 5, bottom panel). These discrepancies provide evidence that issues 
can arise due to spatial and temporal representativeness of the radio-sounding wind velocity retrieval.

\section{Conclusions}

A $0.355 \mu \mathrm{m}$ wind lidar was deployed at the Haute-Provence Observatory in July 1999, to be compared with other wind lidar, a $72 \mathrm{MHz}$ radar and GPS radio soundings. Twelve data sets were acquired in different atmospheric conditions (clear sky, cloudy, strong wind, high aerosol loading, etc.). The radio soundings launched at OHP site were used as a reference. The comparison provided evidence of a good agreement between $0.355 \mu \mathrm{m}$ lidar and radio sounding wind profiles, both in cross-correlation coefficient (with a CC average value of 0.78 ) and RMSE (average value of $3.67 \mathrm{~m} \mathrm{~s}^{-1}$ ). The cross-correlation coefficients for all instruments show a better agreement to the east direction than to the north direction, especially in the lower troposphere. This can be explained by the local topography around the Haute-Provence Observatory site. The absolute deviation is not completely explained by the instrumental error. Different probed volumes can explain it as the radio soundings drifted far away from the launching pad and by local topography.

It has been found that the scattering from particles contaminates the $0.355 \mu \mathrm{m}$ lidar wind velocity measurement. Indeed, even though the Fabry-Perot interferometer was designed to eliminate this impact by defining a so-called crossover region (Flesia and Korb, 1999), the crossover region is not unique but depends on atmospheric conditions.

The methodology discussed here will be a valid support in future ESA Aeolus validation campaigns involving different kinds of instruments.

Acknowledgements. Special thanks to C. Hirt (Université de Genève), R. Wilson (ST-Radar) and OHP personnel for hosting the campaign and for the technical support. The data sets for the $10.6 \mu \mathrm{m}$ lidar and $0.532 \mu \mathrm{m}$ are taken from the database built under ESA support.

Edited by: V. Rizi

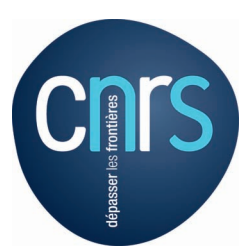

The publication of this article is financed by CNRS-INSU.

\section{References}

Bruneau, D.: Fringe-imaging Mach-Zehnder interferometer as a spectral analyzer for molecular Doppler wind lidar, Appl. Optics, 41, 503-510, 2002.

Cezard, N., Dolfi-Bouteyre, A., Huignard, J. P., and Flamant, P.: Performance evaluation of a dual fringe-imaging Michelson interferometer for air parameter measurements with a $355 \mathrm{~nm}$ Rayleigh-Mie lidar, Appl. Optics, 48, 2321-2332, 2009.

Chanin, M.-L., Garnier, A., Hauchecorne, A., and Porteneuve, J.: A Doppler lidar for measuring winds in the middle atmosphere, Geophys. Res. Lett., 16, 1273-1276, 1989.

Chanin, M.-L., Hauchecorne, A., Garnier, A., and Nedeljkovic, D.: Recent lidar developments to monitor stratosphere-troposphere exchange, J. Atmos. Terr. Phys., 56, 1073-1081, 1994.

Courtier, P., Gauthier, P., Rabier, F., Flamant, P., Dabas, A., Lieutaud, F., and Renault, H.: Study of preparation for the use of Doppler wind lidar information in meteorological assimilation systems, ESA-CR(P)-3453, ESA Publications Division, European Space Agency, Noordwijk, the Netherlands, p. 82, 1992.

Delaval, A., Flamant, P. H., Aupierre, M., Delville, P., Loth, C. Garnier, A., Souprayen, C., Bruneau, D., Le Rille, O., Wilson, R., Vialle, C., Rees, D., Vaughan, M., and Hardesty, R. M.: Intercomparison of wind profiling instruments during the VALID field campaign, in: Advances in Laser Remote Sensing, Selected Papers Presented at the 20th International Laser Radar Conference, edited by: Dabas, A., Loth, C., and Pelon, J., Editions de l'Ecole Polytechnique, Palaiseau Cedex, France, 101-104, 2000a.

Delaval A., Flamant, P. H., Loth, C., Garnier, A., Vialle, C., Bruneau, D., Wilson, R., and Rees, D.: Performance Validation of Direct Detection and Heterodyne Detection Doppler WIND Lidars, Final Report VALID, CNRS/IPSL, available from ESAESTEC, Nordwijk, the Netherlands, p. 76, $2000 \mathrm{~b}$.

Delville, P.: Development of a Coherent Doppler Laser Radar: Simulation and experimental studies of the transceiver and the heterodyne receiver, PhD Thesis, University Paris 6, Paris, France, 179 pp., 1996.

Drobinski, P., Brown, R. A., Flamant, P. H., and Pelon, J.: Evidence of organized large eddies by ground-based Doppler lidar, sonic anemometer and sodar, Bound.-Lay. Meteorol., 88, 343361, 1998.

Flesia, C. and Korb, C.: Theory of the Double-Edge Molecular Technique for Doppler Lidar Wind Measurement, Appl. Optics, 38, 432-440, 1999.

Flesia, C., Korb, C., and Hirt, C.: Double-edge molecular measurement of lidar wind profiles at $355 \mathrm{~nm}$, Opt. Lett., 25, 1466-1468, 2000.

Friedman, J. S., Tepley, C. A., Castleberg, P. A., and Roe, H.: Middle-atmospheric Doppler lidar using an iodine-vapor edge filter, Opt. Lett., 22, 1648-1650, 1997.

Garnier, A. and Chanin, M.-L.: Description of a Doppler Rayleigh Lidar for measuring winds in the middle atmosphere, Appl. Phys. B, 55, 25-40, 1992.

Gentry, B. and Korb, C. L.: Edge Technique for High Accuracy Doppler Velocimetry, Appl. Optics, 33, 5770-5777, 1994.

Gentry, B., Chen, M. H., and Li, S. X.: Wind Measurements with a $355 \mathrm{~nm}$ Molecular Doppler Lidar, Opt. Lett., 25, 1231-1233, 2000. 
Huffaker, R. M., Lawrence, T. R., Post, M. J., Priestley, J. T., Hall Jr., F. F., Richter, R. A., and Keeler, R. J.: Feasibility studies for a global wind measuring satellite system (Windsat): analysis of simulated performance, Appl. Optics, 23, 2523-2536, 1984.

Korb, C. L. and Gentry, B. M.: New Doppler lidar methods for atmospheric wind measurements by the edge technique, in: Conference on Lasers and Electro-Optics, Vol. 7 of 1990 OSA Technical Digest Series, Optical Society of America, Washington, D.C., 322-324, 1990.

Korb, C. L., Gentry, B., Li, S., and Flesia, C.: Theory of the DoubleEdge Technique for Doppler Lidar Wind Measurement, Appl. Optics, 37, 3097-3104, 1998.

Liu, Z. S., Chen, W. B., Zhang, T. L., Hair, J. W., and She, C. Y.: An incoherent Doppler lidar for ground-based atmospheric wind profiling, Appl. Phys. B, 64, 561-566, 1997.

Marseille, G. J. and Stoffelen, A.: Simulation of Wind Profiles from a space-borne Doppler Wind Lidar, Q. J. Roy. Meteorol. Soc., 129, 3079-3098, doi:10.1256/qj.02.96, 2003.

Marksteiner U., Reitebuch, O., Rahm, S., Nikolaus, I., Lemmerz, C., and Witschas, B.: Airborne direct-detection and coherent wind lidar measurements along the east coast of Greenland in 2009 supporting ESA's Aeolus, Proc. SPIE, 8182, 81820J-181820J-8, 2011.

McGill M., Skinner, W., and Irgang, T.: Validation of wind profiles measured with incoherent Doppler lidar, Appl. Optics, 36, 19281932, 1997.

Menzies, R. T. and Tratt, D. M.: Airborne $\mathrm{CO}_{2}$ coherent lidar for measurements of atmospheric aerosol and cloud backscatter, Appl. Optics, 33, 5698-5711, 1994.

Menzies, R. T. and Tratt, D. M.: Airborne lidar observations of tropospheric aerosols during the GLOBE Pacific circumnavigation missions of 1989 and 1990, J. Geophys. Res., 102, 3701-3714, 1997.

Menzies, R. T., Tratt, D. M., and Hunt, W. H.: Lidar In-Space Technology and effective reflectance of oceanic whitecaps, Appl. Optics, 23, 1816-1824, 1984.

Menzies R. T., Tratt, D. M., and Flamant, P. H.: Airborne $\mathrm{CO}_{2}$ coherent lidar measurements of cloud backscatter and opacity over the ocean surfacem, J. Atmos. Ocean. Tech., 11, 770-778, 1994.

National Standard for Spatial Data Accuracy - NSSDA: FGDCSTD-007.3-1998, US Army, Washington, D.C., 1998.

Post, M. J., Richter, R. A., Hardesty, R. M., Lawrence, T. R., and Hall Jr., F. F.: NOAA's Pulsed, Coherent, IR Doppler Lidar Characteristics and Data, Proc. Soc. Photo-Opt. Instrum. Eng., 300, 60-65, 1982.
Reitebuch, O., Werner, Ch., Leike, I., Delville, P., Flamant, P. H., Cress, A., and Engelbart, D.: Experimental Validation of Wind Profiling Performed by the Airborne $10 \mu \mathrm{m}$-Heterodyne Doppler Lidar WIND, J. Atmos. Ocean. Tech., 18, 1331-1344, 2001.

Reitebuch O., Volkert, H., Werner, Ch., Dabas, A., Delville, P., Drobinski, Ph., Flamant, P. H., Richard, E.: “ Determination of air flow across the Alpine ridge by a combination of airborne Doppler lidar, routine radiosounding and numerical simulation". Q. J. Roy. Meteorol. Soc., 129, 715-728, 2003.

Reitebuch, O., Lemmerz, C., Nagel, E., Paffrath, U., Durand, Y., Endemann, M., Fabre, F., and Chaloupy, M.: The Airborne Demonstrator for the Direct-Detection Doppler Wind Lidar ALADIN on ADM-Aeolus, Part I: Instrument Design and Comparison to Satellite Instrument, J. Atmos. Ocean. Tech., 26, 2501-2515, 2009.

Souprayen, C. A., Garnier, A., Hertzog, A., Hauchecorne, A., and Porteneuve, J.: Rayleigh-Mie Doppler wind lidar for atmospheric measurement, I. Instrumental set-up, validation and first climatological results, Appl. Optics, 38, 2410-2421, 1999a.

Souprayen, C. A., Garnier, A., Hertzog, A., Hauchecorne, A., and Porteneuve, J.: Rayleigh-Mie Doppler wind lidar for atmospheric measurements: Part II: Mie scattering effect, theory, and calibration, Appl. Optics, 38, 2422-2431, 1999 b.

Stoffelen, A., Pailleux, J., Källen, E., Vaughan, J. M., Isaksen, L., Flamant, P. H., Wergen, W., Andersson, E., Schyberg, H., Culoma, A., Meynard, R., Endemann, M., and Ingmann, P.: The Atmospheric Dynamics Mission for global wind field measurement, Bull. Atmos. Meteorol. Soc., 86, 73-87, 2005.

Sugawara, A. and Yip, S.: 'Kinetic model analysis of light scattering by molecular gases, Phys. Fluids, 18, 1911-1921, 1967.

Tenti, G. and Desai, R. D.: Kinetic theory of molecular gases I/models of the linear Waldmann-Snider collision operator, Can. J. Phys., 53, 1266-1278, 1974.

Tenti, G., Boley, C. D., and Desai, R. D.: On the kinetic model description of Rayleigh-Brillouin scattering from molecular gases, Can. J. Phys., 52, 285-290, 1974.

Werner, Ch., Flamant, P. H., Reitebuch, O., Köpp, F., Streicher, J., Rahm, S., Nagel, E., Klier, M., Hermann, H., Loth, C., Delville, P., Drobinski, P., Romand, B., Boitel, Ch., Oh, D., Lopez, M., Meissonnier, M., Bruneau, D., and Dabas, A. M.: WIND Infrared Doppler Lidar Instrument, Opt. Eng., 40, 115-125, 2001.

Woodman, R. F. and Guillen, A.: Radar observations of winds and turbulence in the stratosphere and mesosphere, J. Atmos. Sci., 31, 493-503, 1974. 